\title{
Effect of Acute Hyperinsulinemia on Brain Metabolism Evaluated by 1H MR Spectroscopy - a Pilot Study
}

\author{
S. KRATOCHVÍLOVÁ ${ }^{1}$, A. ŠKOCH ${ }^{1}$, M. DEZORTOVÁ ${ }^{1}$, E. ŠVEHLÍKOVÁ ${ }^{1}$, M. HILL $^{2}$, \\ J. BRUNOVÁ ${ }^{1}$, M. HÁJEK ${ }^{1}$, T. PELIKÁNOVÁ ${ }^{1}$ \\ ${ }^{1}$ Institute for Clinical and Experimental Medicine, Prague, Czech Republic, ${ }^{2}$ Institute of \\ Endocrinology, Prague, Czech Republic
}

Received January 2, 2013

Accepted January 10, 2014

On-line April 3, 2014

\section{Summary}

To determine whether acutely-induced supraphysiological hyperinsulinemia influences brain metabolism in patients with type 1 diabetes (D) and healthy controls (C) as detected by MR Spectroscopy. Group D consisted of 4 patients with the average duration of diabetes for 7 years. They were matched according to age, sex and BMI to 4 healthy controls. 1H MR Spectroscopy was performed with a 1.5 Tesla. Spectra were obtained from parietooccipital white matter repeatedly during a 3-h hyperinsulinemic euglycemic clamp with $2 \mathrm{mU} \cdot \mathrm{kg}^{-1} \cdot \mathrm{min}^{-1}$. In group $D$, significantly lower basal concentrations of $\mathrm{N}$-acetylaspartate $(p=0.02)$, choline $(p=0.03)$, creatine $(p=0.002)$ and inositol $(p=0.007)$ were detected compared to $C$. After the induction of hyperinsulinemia, concentrations of choline, creatine, GABA, inositol, lactate, NAA and composite signal glutamate + glutamine (Glx) stayed stable. The detection of glucose signal is less realiable at 1.5 Tesla but we registered the alteration in glucose concentration $(p=0.003)$ in the whole group. Originally sightly elevated glucose concentration in $\mathrm{D}$ decreased on the contrary to the increase of originally lower glucose level in C. In conclusions, brain metabolism was altered in D. Short term supraphysiological euglycemic hyperinsulinemia induced changes in the concentration of brain glucose in both $C$ and $D$.

\section{Key words}

Brain glucose metabolism - Hyperinsulinemic clamp • Magnetic resonance spectroscopy • Type 1 diabetes

\section{Corresponding author}

T. Pelikánová, Diabetes Center, Institute for Clinical and Experimental Medicine, Vídeňská 1958/9, 14021 Prague, Czech Republic. Fax: +420 261362 820. E-mail: tepe@ikem.cz

\section{Introduction}

Insulin is an important neuromodulator. Insulin receptors are found throughout the brain, particularly in the hypothalamus and hippocampus (Havrankova et al. 1978). Glucose serves as a primary fuel for the brain and continuous supply is necessary. Glucose enters the brain by the process of facilitated diffusion across the blood-brain barrier (BBB) down the concentration gradient. Glucose transport is regulated through a network of GLUT transporters. The GLUT-1 transporter is the principal glucose transporter isoform within the $\mathrm{BBB}$ and is insulin insensitive. However, GLUT 4 transporters are insulin sensitive and are also present at the BBB. (McEwen et al. 2004).

The question whether and in which manner insulin can influence glucose transfer across the BBB and its further metabolization has not been definitely answered. Most of the studies support the hypothesis that insulin does not promote glucose transfer across the BBB (Eastman et al. 1990, Cranston et al. 1998, Hasselbalch et al. 1999, Seaquist et al. 2001). However, an increase in glucose accumulation after the insulin administration has also been documented (Hertz et al. 1981, Bingham et al. 2002, Anthony et al. 2006).

The posibilities of the direct measurement of glucose concentration are limited. $1 \mathrm{H}$ nuclear magnetic resonance spectroscopy (MRS) is the only non-invasive method that allows direct measurement of native glucose concentration in the human brain in vivo and enables also quantification of other metabolites, such as inositol, choline, creatine, glutamine, glutamate, GABA, 
$\mathrm{N}$-acetylaspartate and lactate.

The aim of our study was to evaluate the effect of acute hyperinsulinemia induced in vivo by clamp on the brain metabolism detectable by $1 \mathrm{H}$ MRS in subjects with type 1 diabetes and healthy controls.

\section{Materials and Methods}

Subjects

A group of patients with type 1 diabetes (D) was matched for sex, age and body mass index (BMI) to a group of healthy controls (C) without a family history of diabetes mellitus and with normal glucose tolerance confirmed during an oral glucose tolerance test using criteria defined by the Expert Committee on the Diagnosis and Classification of Diabetes Mellitus (2003). Subjects in group D were treated either with 4 injections of insulin per day or with an insulin pump and were without any microvascular complication, cerebrovascular disorder, history of severe hypoglycemia and were $\mathrm{C}$ peptide negative. The clinical and biochemical characteristics of the two groups are summarized in Table 1. Written informed consent was obtained from each participant after explaining the purpose, nature and potential risks of the study. The study protocol was approved by the local ethics committee.

\section{Procedures}

Subjects were examined on an outpatient basis after an overnight fast. Patients treated with insulin were instructed either to inject a normal dose of intermediate acting insulin at $22: 00$ or to keep their usual rate of subcutaneous insulin by insulin pump. The insulin pump was stopped $90 \mathrm{~min}$ before the beginning of the clamp. At the beginning of the study, the subject was placed in a supine position into the MR imager and the first measurement was performed. After finishing the basal spectrum, the clamp study started. The final spectrum was obtained after $160 \mathrm{~min}$.

\section{Hyperinsulinemic-euglycemic clamp}

The hyperinsulinemic-euglycemic clamp study taking $3 \mathrm{~h}$ was performed as previously described (De Fronzo et al. 1979). The rate of the continuous insulin infusion (Actrapid HM $100 \mathrm{U} / \mathrm{ml}$, Novo Nordisk, Copenhagen, Denmark) was kept at $2 \mathrm{mU} \cdot \mathrm{kg}^{-1} \cdot \mathrm{min}^{-1}$ (resulting in constant hyperinsulinemia of approximately $140 \mu \mathrm{U} \cdot \mathrm{ml}^{-1}$ ). The rate of the $15 \%$ glucose infusion was adjusted to maintain glycemia 5 mmol. $\mathrm{l}^{-1}$. Whole-body insulin sensitivity was calculated from the mean glucose infusion rate in the final steady-state period during the clamp (160-180 min) divided by body weight and expressed as glucose disposal (M).

Table 1. Clinical characteristics of the study groups.

\begin{tabular}{|c|c|c|}
\hline & Diabetics & Controls \\
\hline$N$ & 4 & 4 \\
\hline Age (years) & $24.0 \pm 2.3$ & $27.0 \pm 2.2$ \\
\hline $\begin{array}{l}\text { Disease duration } \\
\text { (years) }\end{array}$ & $7.5 \pm 4.7$ & / \\
\hline$B M I\left(k g \cdot m^{-2}\right)$ & $23.7 \pm 2.1$ & $24.9 \pm 3.8$ \\
\hline$W H R$ & $0.83 \pm 0.09$ & $0.88 \pm 0.04$ \\
\hline HbAlc (mmol.mol $\left.{ }^{-1}\right)$ & $51 \pm 11$ & $29 \pm 5.0$ \\
\hline Systolic BP (mm Hg) & $115.0 \pm 4.1$ & $118.3 \pm 7.7$ \\
\hline Diastolic BP ( $\mathrm{mm} \mathrm{Hg})$ & $76.3 \pm 4.8$ & $75.5 \pm 6.4$ \\
\hline $\begin{array}{l}\text { Cholesterol total } \\
\left(\mathrm{mmol} . l^{-1}\right)\end{array}$ & $4.4 \pm 1.0$ & $4.8 \pm 0.6$ \\
\hline HDL (mmol.l $\left.l^{-1}\right)$ & $1.5 \pm 0.2$ & $1.5 \pm 0.2$ \\
\hline$L D L\left(\right.$ mmol. $\left.l^{-1}\right)$ & $2.6 \pm 0.9$ & $3.0 \pm 0.9$ \\
\hline$T A G\left(m m o l . l^{-1}\right)$ & $0.96 \pm 0.4$ & $0.78 \pm 0.3$ \\
\hline$M\left(\mathrm{mg} \mathrm{kg}^{-1} \cdot \mathrm{min}^{-1}\right)$ & $8.66 \pm 3.1$ & $9.29 \pm 3.0$ \\
\hline
\end{tabular}

Data are means $\pm \mathrm{SD}$; BMI, body mass index; WHR, waist-to-hip ratio; HbA1c, glycosylated hemoglobin (IFCC); BP, blood pressure; HDL, high-density lipoprotein cholesterol; LDL, lowdensity lipoprotein cholesterol; TAG, serum triglycerides; $M$, glucose disposal; MCR, metabolic clearance rate of glucose.

\section{MR examination}

Measurements of MR spectra were performed by a Siemens Vision 1.5T MR scanner in a circularly polarized single channel head coil. Standard T2 weighted images in three perpendicular planes were used for the positioning of the voxel (VOI) for the consecutive spectroscopy measurement. The MR spectra from parietooccipital white matter were acquired by means of single voxel STEAM (Frahm et al. 1989) sequence with water suppression. The following parameters were used: $\mathrm{TR} / \mathrm{TE} / \mathrm{TM}=5000 / 10 / 15 \mathrm{~ms}$, voxel volume $10.7 \pm 0.4 \mathrm{ml}$. The number of acquisitions was 220 , total acquisition time per spectrum was $18.5 \mathrm{~min}$. The quantification from the acquired spectra was done by LCModel routine (LCModel web page). The obtained concentrations were corrected according to the quality control protocol (Hájek et al. 2000). Saturation corrections (T1 and T2) and segmentation were not applied. The concentration of metabolites NAA (N-acetylaspartate + N-acetyl- 
aspartareglutamate), $\mathrm{Cr}$ (creatine + phosphocreatine), Cho (choline compounds), Glc (glucose), GABA, Glx (glutamine + glutamate), Ins (inositol) and Lac (lactate) were obtained as molar concentration [laboratory units]. Data suitable for quantitative comparison of metabolite concentration were considered when Cramer-Rao bound was below $50 \%$, e.g. for NAA, Cr, Cho, Ins and Glx. The other metabolite concentrations were used only for qualitative descriptions.

\section{Laboratory measurements}

Plasma glucose was measured using the glucose oxidase method (Beckman Glucose Analyzer; Beckman Instruments, Fullerton, California, USA). Plasma IRI concentration was determined by radioimmunoassay using an Immunotech Insulin IRMA kit (Immunotec; Prague, Czech Republic). Glycosylated hemoglobin was measured by ion-exchange high-performance liquid chromatography (HPLC) using a Bio-Rad Hemoglobin A1c Column Test (Bio-Rad Laboratories GmbH; Munich, Germany) and for calibration, a method approved by International Federation of Clinical Chemistry and Laboratory Medicine was used (Goodall et al. 2005).

\section{Statistical analysis}

The effect of hyperinsulinemia was evaluated by Repeated Measures ANOVA model including the factors and interactions as follows: Status (C vs D) as the between-factor, Subject factor, Stage of the clamp as the within-factor and Status $\times$ Stage interaction. The last term indicated whether the effect of the hyperinsulinemia on concentrations of selected brain metabolites was different in $\mathrm{C}$ and $\mathrm{D}$. The differences between the subgroups were evaluated using least significant difference multiple comparisons. The statistical significance $\mathrm{p}<0.05$ was chosen for both ANOVA testing and multiple comparisons. Due to non-Gaussian data distribution in all dependent variables, the data underwent power transformations to attain distributional symmetry and a constant variance in the data as well as in residuals. The non-homogenities were detected using residual diagnostics. The experimental points with absolute values of Studentized residual (after data transformation) greater than 3 were excluded from the analysis. The fraction of such points never exceeded $5 \%$ of the total number. Statgraphics Plus 5.1 Statistical software from Manugistics (Rockville, MD, USA) was used for the data analysis.

\section{Results}

Basal concentrations of the following metabolites were significantly higher in $C$ than in $D$ : $\mathrm{N}$-acetylaspartate $(p=0.02)$, choline $(p=0.03)$, creatine $(p=0.002)$ and inositol $(p=0.007) \quad$ (Fig. 1). Basal concentrations of glucose, GABA, Glx (glutamine + glutamate) and lactate were comparable.

After the induction of hyperinsulinemia concentrations of choline, creatine, GABA, inositol, lactate, NAA and Glx stayed stable. The concentration of glucose was very low during the clamp but the computer analysis of spectra shows that the induction of hyperinsulinemia altered the glucose concentration $(p=0.003)$ : slightly elevated glucose concentration in D decreased on the contrary to the increase of originally lower glucose level in C (Fig. 1). The impact of hyperinsulinemia was different in both groups $(p=0.015)$.

\section{Discussion}

We found lower basal concentrations of $\mathrm{N}$-acetylaspartate, inositol, choline and creatin in group D compared to C. Our results are only in partial agreement with previously published data. The difference might be explained by the fact that we compared absolute concentrations in laboratory units. Most of the studies listed below considered the creatine concentration in the brain to be stable and use it as an internal standard. Since it is known that creatine concentration can vary under some pathological conditions (Govindaraju et al. 2000) we used the absolute concentration obtained from LCmodel and indeed we found a lower creatine level in D compared with $\mathrm{C}$.

Myoinositol has been proposed as a glial marker (Govindaraju et al. 2000) and during hyperglycemia is formed in abundance (Kreis et al. 1992). Elevation of the myoinositol signal in subjects with diabetes has been noted several times (Kreis et al. 1992, Geissler et al. 2003, Makimattila et al. 2004, Cameron et al. 2005, Sahin et al. 2008, Heikkilä et al. 2009). Only Makimattila, Kreis and Cameron compared direct signal intensities and not ratios to creatin or $\mathrm{H}_{2} \mathrm{O}$ signal. We found a significant decrease of both myoinositol and creatine signal in the group D compared with $C$.

$\mathrm{N}$-acetylaspartate (NAA) serves as a marker of neuronal density and functionality and long lasting hyperglycemia might lead to neuronal damage (Govindaraju et al. 2000). Our finding of the decrease in 

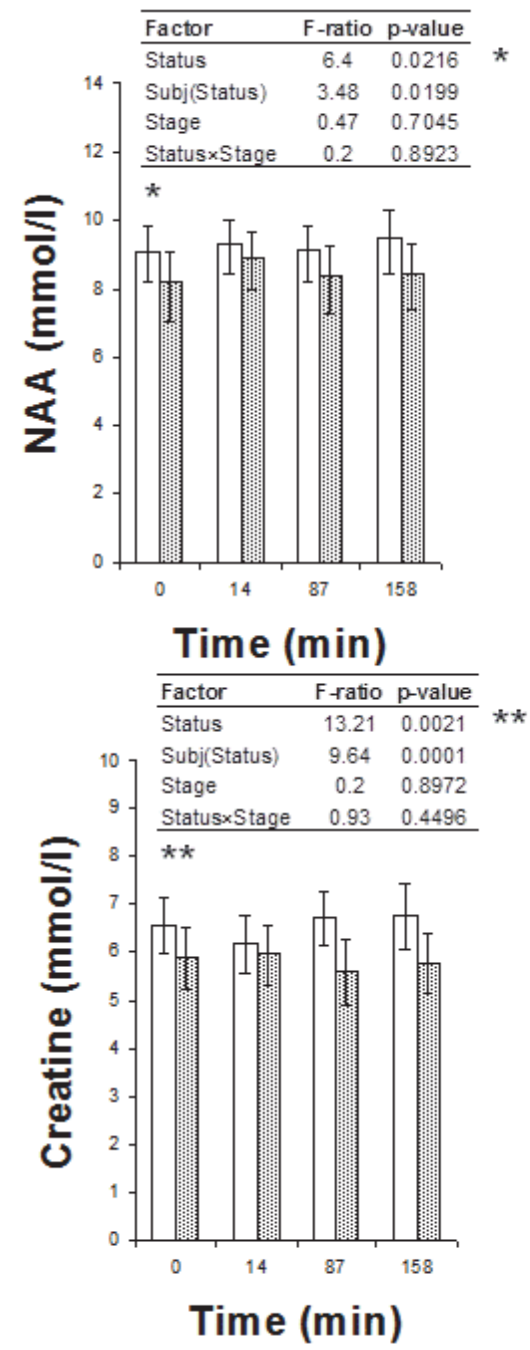

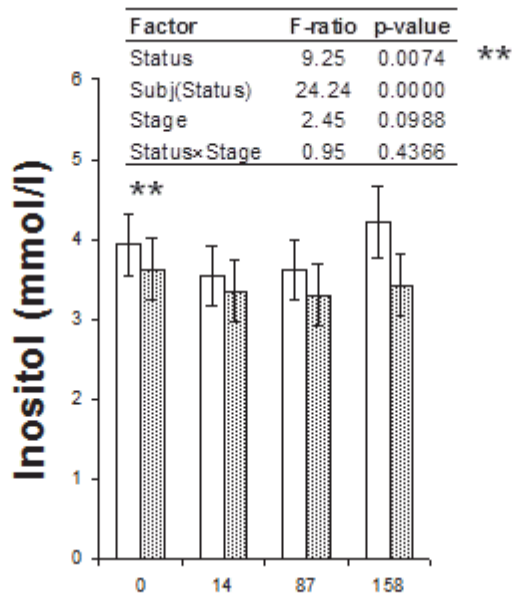

\section{Time (min)}

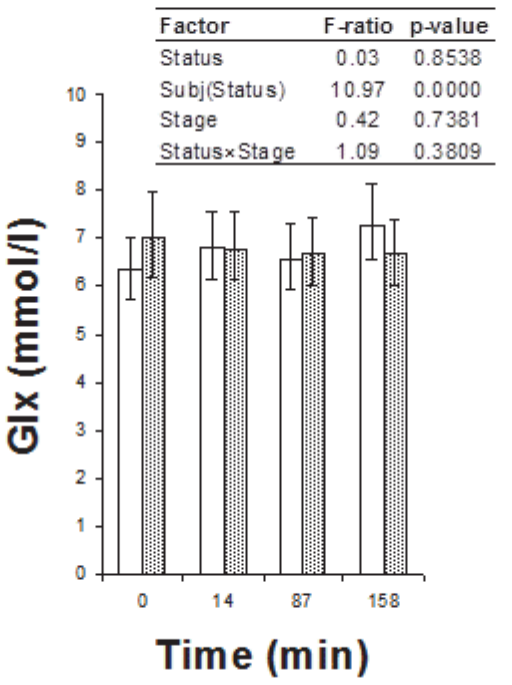

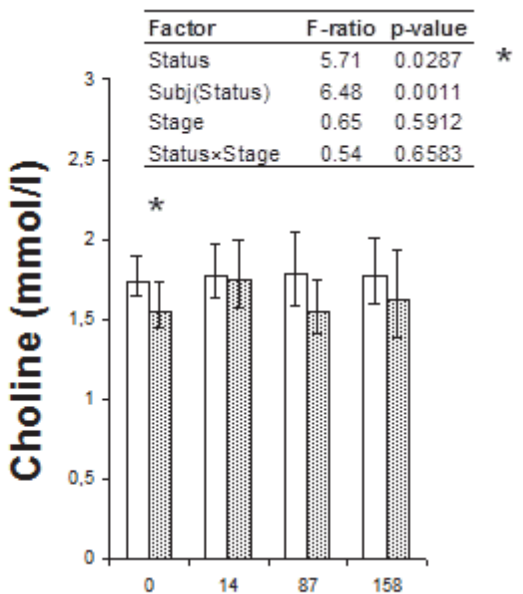

Time (min)

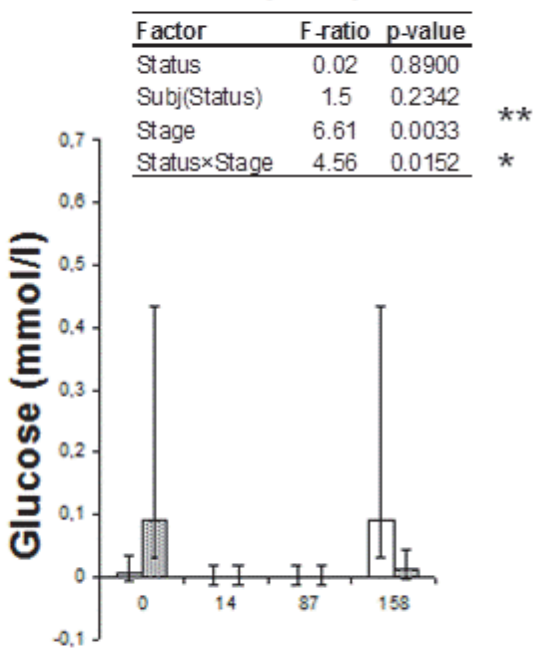

Time $(\min )$

Fig. 1. Brain concentrations of NAA (N-acetylaspartate $+\mathrm{N}$-acetylaspartateglutamate), Ins (inositol), Cho (cholne compounds), $\mathrm{Cr}$ (creatine + phosphocreatine), Glx (glutamate + glutamine) and glucose during the hyperinsulinemic clamp (at 0, 14, 87 and $158 \mathrm{~min}$ ) in groups of $C$ and $D$ subjects. The white (C) and grey (D) bars with error bars represent retransformed mean values with their $95 \%$ confidence intervals for controls and diabetics, respectively. $\mathrm{F}$ in the embedded table symbolize the Fisher's statistics for individual factors and interactions. $\mathrm{P}$ in the embedded table symbolize the statistical significance. The asterisks correspond to significant difference between $\mathrm{C}$ and $\mathrm{D}$ irrespectively of the clamp, in glucose the asterisk corresponds to significant changes during the clamp. $*<0.05 ; * *<0.01$.

NAA signal is in agreement with most of the published studies (Kreis et al. 1992, Sarac et al. 2005, WoottonGorges et al. 2007, Heikkila et al. 2008, Sahin et al. 2008).

Choline peak is formed mainly by phosphocholine and glycerophosphocholine with a small contribution of free choline. Phosphocholine is the major constituent of cell membranes and higher choline concentration is supposed to be a marker of increased membrane turnover (Govindaraju et al. 2000). Kreis et al. (1992), Geissler et al. (2003), Makimattila et al. (2004) and Modi et al. (2008), all describe an elevation of choline in diabetics. In contrast, Sarac et al. (2005) revealed a decrease in choline in parietal white matter in children with poorly controlled diabetes.

Total creatine is the sum of creatine and phosphocreatine. Phosphocreatine serves as a reservoir for the generation of ATP and thus reflects the brain energetic status. Increased creatine is related to increased oxidative metabolism and decreased levels are observed in hypometabolic states (Heikkilä et al. 2008). A decreased ratio of PCr/ATP during 31P MRS study in type 1 diabetics has been already described (Bischof et al. 2004) and reflects the alteration of the energetic metabolism in type 1 diabetes.

After the induction of hyperinsulinemia, concentrations of choline, creatine, inositol, NAA and Glx (composite signal glutamine + glutamate) stayed 
stable during the entire clamp. The glucose signal is hard to resolve using $1.5 \mathrm{~T}$ since its concentration in the brain is close to $1 \mathrm{mmol} \cdot \mathrm{l}^{-1}$. The effect of acutely induced hyperinsulinemia on glucose was different in diabetics and controls. Initially, a slightly elevated glucose concentration in diabetics decreased on the contrary to the increase of originally lower glucose level in controls. However the significance of the finding is uncertain.

The detection of a higher basal glucose concentration in D corresponds with previously published data (Kreis et al. 1992, Makimattila et al. 2004, Heikkilä et al. 2009) and Seaquist et al. (2001) described the linear relationship between plasmatic and cerebral glucose level. The plasmatic glycemia in our study in subjects with diabetes was indeed $2.6 \mathrm{mmol}^{-1}$ higher at the beginning of the clamp.

The question how insulin affects glucose transfer into the brain and its further metabolisation has not yet been definitely answered. The MR study performed by Seaquist et al. (2001) compared brain glucose concentration with or without insulin during hyperglycemia. The insulin infusion was without any significant effect on glucose concentration however it does not exclude higher glucose transfer under the condition that glucose is further metabolized. PET studies are able to quantify the whole amount of glucose that crosses the $\mathrm{BBB}$ no matter whether the molecule stays intact or is integrated further to the metabolism. According to Bingham et al. (2002) and Anthony et al. (2006) and their PET studies, insulin increases the rate of the brain glucose metabolism in comparison with zero insulinemia during somatostatin infusion. In contrast,
Hasselbalch et al. (1999) also using PET did not prove any effect of insulin on glucose blood to brain transport. He admits that insulin may alter the compartmentalization of further glucose metabolism since the glucose transfer from the brain back to blood and the rate of glucose defosforylation both increased significantly during insulin infusion. Similar results were published by Eastman et al. (1990). Cranston et al. (1998) did not find any effect of hyperinsulinemia in type 1 diabetic patients.

In diabetics in our study initially elevated glucose concentration decreased after the induction of hyperinsulinemia and establishment of euglycemia in peripheral circulation and stayed very low through the entire study. On contrary in healthy controls supraphysiological insulinemia induced an increase in the brain glucose level. Our data represent the results of our small pilot study and need further confirmation. Nevertheless it seems that brain glucose transfer and (or) metabolism might respond to a certain extent to hyperinsulinemia.

\section{Conflict of Interest}

There is no conflict of interest.

\section{Acknowledgements}

The skilful technical assistance of Ms. Dana Lapešová, Ms. Dagmar Šišáková, Ms. Jarmila Saudková, Ms. Dana Kobrová and Ms. Šárka Eisenreichová is gratefully acknowledged. Supported by grant from the Health Ministry of the Czech Republic (project MZO 00023001).

\section{References}

ANTHONY K, REED LJ, DUNN JT, BINGHAM E, HOPKINS D, MARSDEN PK, AMIEL SA: Attenuation of insulin - evoked responses inbrain networks controlling appetite and reward in insulin resistance. Diabetes $\mathbf{5 5}$ : 2986-2992, 2006.

BINGHAM EM, HOPKINS D, SMITH D, PERNET A, HALLETT W, REED L, MARSDEN PK, AMIEL SA: The role of insulin in human brain glucose metabolism: an 18Fluoro-Deoxyglucose Positron Emission Tomography Study. Diabetes 51: 3384-3390, 2002.

BISCHOF MG, MLYNARIK V, BREHM A, BERNROIDER E, KRSSAK M, BAUER E, MADL C, BAYERLEEDER M, WALDHÄUSL W, RODEN M: Brain energy metabolism during hypoglycaemia in healthy and type 1 diabetic subjects. Diabetologia 47: 648-651, 2004.

BOYLE PJ, KEMPERS BA, O'CONNOR AM, NAGY RJ: Brain glucose uptake and unawareness of hypoglycemia in patients with insulin-dependent diabetes mellitus. N Engl J Med 333: 1726-1731, 1995.

CAMERON FJ, KEAN MJ, WELLARD RM, WERTHER GA, NEIL JJ, INDER TE: Insights into the acute cerebral metabolic changes associated with childhood diabetes. Diabet Med 22: 648-653, 2005. 
CRANSTON I, MARSDEN P, MATYKA K, EVANS M, LOMAS J, SONKSEN P, MAISEY M, AMIEL SA: Regional differences in cerebral blood flow and glucose utilization in diabetic man: the effect of insulin. J Cereb Blood Flow Metab 18: 130-140, 1998.

DEFRONZO RA, TOBIN JD, ANDRES R: Glucose clamp technique: a method for quantifying insulin secretion and resistance. Am J Physiol 237: E214-E223, 1979.

EASTMAN RC, CARSON RE, GORDON MR, BERG GW, LILLIOJA S, LARSON SM, ROTH J: Brain glucose metabolism in noninsulin-dependent diabetes mellitus: a study in Pima Indians. J Clin Endocrinol Metab 71: 1602-1610, 1990.

EXPERT COMMITTEE ON THE DIAGNOSIS AND CLASSIFICATION OF DIABETES MELLITUS: Follow-up report on the diagnosis of diabetes mellitus. Diabetes Care 26: 3160-3167, 2003.

FRAHM J, BRUHN H, GYNGELL ML, MERBOLDT KD, HÄNICKE W, SAUTER R: Localized high-resolution proton NMR spectroscopy using stimulated echoes: initial applications to human brain in vivo. Magn Reson Med 9: 79-93, 1989.

GEISSLER A, FRÜND R, SCHÖLMERICH J, FEUERBACH S, ZIETZ B: Alterations of cerebral metabolism in patients with diabetes mellitus studied by proton magnetic resonance spectroscopy. Exp Clin Endocrinol Diabetes 111: 421-427, 2003.

GOODALL I: HbA1c standardisation destination-global IFCC Standardisation. How, why, where and when - a tortuous pathway from kit manufacturers, via inter-laboratory lyophilized and whole blood comparisons to designated national comparison schemes. Clin Biochem Rev 26: 5-19, 2005.

GOVINDARAJU V, YOUNG K, MAUDSLEY AA: Proton NMR chemical shifts and coupling constants for brain metabolites. NMR Biomed 13: 129-153, 2000.

HÁJEK M, BURIAN M, DEZORTOVÁ M: Application of LCModel for quality control and quantitative in vivo $1 \mathrm{H}$ MR spectroscopy by short echo time STEAM sequence. Magma 10: 6-17, 2000.

HASSELBALCH SG, KNUDSEN KM, JAKOBSEN J, HAGEMAN LP, HOLM P, PAULSON OB: Blood-brain barrier permeability of glucose and ketone bodies during short-term starvation in humans. Am J Physiol 268: E1161-E1166, 1995.

HASSELBALCH SG, KNUDSEN GM, VIDEBAEK C, PINBORG LH, SCHMIDT JF, HOLM S, PAULSON OB: No effect of insulin on glucose blood brain barrier transport and cerebral metabolism in humans. Diabetes 48 : 1915-1921, 1999.

HAVRANKOVA J, ROTH J, BROWNSTEIN M: Insulin receptors are widely distributed in the central nervous system of the rat. Nature 272: 827-829, 1978.

HEIKKILÄ O, LUNDBOM N, TIMONEN M, GROOP PH, HEIKKINEN S, MÄKIMATTILA S: Hyperglycaemia is associated with changes in the regional concentrations of glucose and myo-inositol within the brain. Diabetologia 52: 534-540, 2009.

HERTZ MM, PAULSEN OB, BARRY DI, CHRISTIANSEN JS, SVENDSEN PA: Insulin increases glucose transfer across the blood-brain barrier in man. J Clin Invest 67: 597-604, 1981.

JÍRŮ F, DEZORTOVÁ M, BURIAN M, HÁJEK M: The role of relaxation time corrections for the evaluation of long and short echo time $1 \mathrm{H}$ MR spectra of the hippocampus by NUMARIS and LCModel techniques. Magn Reson Mater Phy 16: 135-142, 2003.

KREIS R, ROSS BD: Cerebral metabolic disturbancies in patients with subacute and chronic diabetes mellitus: detection with proton MR Spectroscopy. Radiology 184: 123-130, 1992.

LCModel web page: http://www.s-provencher.com/pages/lcmodel.shtml

MÄKIMATTILA S, MALMBERG-CEDER K, HAKKINEN AM, VUORI K, SALONEN O, SUMMANEN P, YKI-JÄRVINEN H, KASTE M, HEIKKINEN S, LUNDBOM N, ROINE RO: Brain metabolic alterations in patients with type 1 diabetes - hyperglycemia induces injury. J Cereb Blood Flow Metab 24: 1393-1399, 2004.

MCEWEN BS, REAGAN LP: Glucose transporter expression in the central nervous system: relationship to synaptic function. Eur J Pharmacol 490: 13-241, 2004.

MODI S, BHATTACHARYA M, SEKHRI T, RANA P, TRIPATHI RP, KHUSHU S: Assessment of the metabolic profile in Type 2 diabetes mellitus and hypothyroidism through proton MR spectroscopy. Magn Reson Imaging 26: 420-425, 2008. 
MOORADIAN AD: Central nervous system complications of diabetes mellitus - a perspective from the blood brain barrier. Brain Res Rev 23: 210-218, 1997.

PROVENCHER SW: Estimation of metabolite concentrations from localized in vivo proton NMR spectra. Magn Reson Med 30: 672-679, 1993.

SAHIN I, ALKAN A, KESKIN L, CIKIM A, KARAKAS HM, FIRAT AK, SIGIRCI A: Evaluation of in vivo cerebral metabolism on proton magnetic resonance spectroscopy in patients with impaired glucose tolerance and type 2 diabetes mellitus. $J$ Diabetes Complications 22: 254-260, 2008.

SARAC K, AKINCI A, ALKAN A, ASLAN M, BAYSAL T, OZCAN C: Brain metabolite changes on proton magnetic resonance spectroscopy in children with poorly controlled type 1 diabetes mellitus. Neuroradiology 47: $562-565,2005$.

SEAQUIST ER, DAMBERG GS, TKAC I, GRUETTER R: The effect of insulin on in vivo cerebral glucose concentrations and rates of glucose transport/metabolism in humans. Diabetes 50: 2203-2209, 2001.

WOOTTON-GORGES SL, BUONOCORE MH, KUPPERMANN N, MARCIN JP, BARNES PD, NEELY EK, DICARLO J, MCCARTHY T, GLASER NS: Cerebral proton magnetic resonance spectroscopy in children with diabetic ketoacidosis. Am J Neuroradiol 28: 895-899, 2007. 